\title{
Interannual modulation of seasonal glacial velocity variations in the Eastern Karakoram detected by ALOS-1/2 data
}

\author{
MUHAMMAD USMAN, ${ }^{1}$ MASATO FURUYA ${ }^{2}$ \\ ${ }^{1}$ Department of Natural History Sciences, Hokkaido University, N10W8, Kita-ku, Sapporo 060-0810, Japan \\ ${ }^{2}$ Department of Earth and Planetary Sciences, Hokkaido University, N10W8, Kita-ku, Sapporo 060-0810, Japan \\ Correspondence: Muhammad Usman <usman.lal@frontier.hokudai.ac.jp>
}

\begin{abstract}
Unlike in most other regions, Karakoram glaciers are either stable or advancing, a phenomenon known as the Karakoram anomaly. Despite studies of glacier surges and the derivation of surface velocity maps, the spatiotemporal variability of glacier dynamics still remains poorly understood, particularly in the Eastern Karakoram Range. We use Advanced Land Observing Satellite/the Phased Array type L-band Synthetic Aperture Radar (ALOS/PALSAR)-1/2 data from 2007 to 2011 and 2014 to 2015 to examine detailed surface velocity patterns of the Siachen, Baltoro, Kundos, Singkhu and Gasherbrum Glaciers. The first three glaciers show considerable velocity variability $\left(20-350 \mathrm{~m} \mathrm{a}^{-1}\right)$, with clear seasonal patterns. Although all glaciers, except for Baltoro, flow slowest in 2015, the velocity structures are individual and vary in space and time. In Gasherbrum Glacier, peak surge-phase velocities are seasonally modulated, with maxima in summers 2006 and 2007, suggesting surface melt plays an important role in maintaining the active phase. Given the relatively close proximity of these glaciers, we assume that surface melt timing and rates are comparable. We therefore argue that the observed spatiotemporal and interannual velocity patterns are determined by local and internal mechanisms, including englacial and subglacial hydrology, thermal processes and tributary configuration of each individual glacier.
\end{abstract}

KEYWORDS: glacier velocity, interannual modulation, L-band SAR, pixel offset, summer speed-up

\section{INTRODUCTION}

High-mountain regions with glaciers act as 'water towers' for the lowlands, as they provide meltwater not only to the people living close to the mountains, but also to the lowlands via runoff that recharges the river-fed aquifers. Also, through this runoff, such regions affect global sea level (Bolch and others, 2012). The Karakoram is the fourth largest area of glacier cover on Earth (Dyurgerov and Meier, 2005), with an estimated glacial area of 18000 square kilometers (Bolch and others, 2012). This region has a diverse vertical distribution of glaciers, ranging in elevation from $2300 \mathrm{~m}$ a. s.l. in the Hunza valley to $6300 \mathrm{~m}$ on K2 (Hewitt, 2006).

The Karakoram glaciers are fed by precipitation and avalanche. This precipitation has been increasing at elevations near 2500 and $4800 \mathrm{~m}$, but has maximum values between 5000 and $6000 \mathrm{~m}$ (Hewitt, 2005). Within the region, westerly disturbances in winter bring around two-thirds of the highaltitude snow (Hewitt and others, 1988) and Indian monsoons in summer bring much of the remaining accumulation (Benn and Owen, 1998; Hewitt, 2005; Bookhagen and Burbank, 2010; Palazzi and others, 2015).

Concerning the terminus positions of these glaciers, mapping and field observations found a $5 \%$ retreat in the early 20th century (Hewitt, 2011). The retreat slowed down in the 1970s, and then stabilized in the 1990s, when those in the high Karakoram starting to advance (Mayewski and Jeschke, 1979; Hewitt, 2005). The trend remains variable, with the GRACE satellite gravimetric observations in 20032009 showing a net loss in mass of glaciers across the high Asian mountains, but the northwestern part including the Karakoram mountain range showing a gain in mass
(Matsuo and Heki, 2010). Similarly, digital elevation model (DEM) data acquired from the Shuttle Radar Topographic Mission (SRTM) (Farr and others, 2007) and Satellite Pour I'Observation de la Terre (SPOT5) optical stereo imagery show that a slight gain in the mass in the central Karakoram glaciers occurred in the period 1999-2008 epoch (Gardelle and others, 2012).

The Karakoram anomaly may be caused by a higher transport of summer monsoonal moisture that not only increases snowfall at high altitudes, but also increases cloudiness and cooling in summers (Farhan and others, 2015; Zafar and others, 2016). Another view is that the reason for the resiliency of Karakoram glaciers could be by these due to a higher contribution of winter snowfall compared with monsoon snowfall (Kapnick and others, 2014).

But to better understand the mechanisms of the Karakoram anomaly, we should consider that the Karakoram Range has a relatively high density of surge-type glaciers (e.g. Hewitt, 1969, 2007, 2011; Bhambri and others, 2017). A surgetype glacier has a recurring active phase, also known as the surging phase, and a quiescent phase. During the active phase, the velocities are higher by a factor of 10-100 over a time period ranging from few months to years. In this phase, the terminal position may advance by up to several kilometers. On the other hand, the quiescent phase, also known as normal flow, can last tens to hundreds of years (Jiskoot, 2011). Surge dynamics in the Karakoram have thus been extensively studied (Mayer and others, 2011; Quincey and others, 2011; Heid and Kääb, 2012; Rankl and others, 2014; Quincey and Luckman, 2014; Quincey 
and others, 2015; Paul and others, 2017). But it is still not clear whether the Karakoram anomaly has a correlation with the surge dynamics in the Karakoram Range. To answer this question, Copland and others (2011) suggested that the recent positive mass balance in the Karakoram played a role in the doubling in number of new surging episodes during the 14-year period before and after 1990 . However, the number of surge-type glaciers in their active phase has decreased since 1999, which is hard to explain only by the changes in mass balance, thus suggesting complexity in the surging mechanisms (Rankl and others, 2014). In particular, spatial and temporal changes in the thermal regime and the role of meltwater in en- and subglacial hydrology are poorly known for the Karakoram Range. Quincey and others (2015) concluded that neither the thermal, nor the hydrological model of surging can account for the observed surges.

To develop a better model, comprehensive in situ observations would be ideal, but because of the remoteness and logistic issues in the Karakoram, it would be practically impossible to perform extensive in situ observations. Instead, surface velocity maps over the Karakoram Range have been presented (e.g. Rankl and others, 2014). However, most previous velocity maps are either snapshots of a particular period or they have limited temporal resolution. Hence, the variability in seasonal velocity changes and even the presence of the seasonality itself have been uncertain.

To help clarify the mechanisms associated with glacial dynamics in the Eastern Karakoram Range, we report here on the spatial and temporal variability of glacier velocities with unprecedented resolution in this region. We use the Lband synthetic aperture radar (SAR) images acquired by the Phased Array type L-band Synthetic Aperture Radar (PALSAR) sensors of Advanced Land Observing Satellite (ALOS)-1 and ALOS-2, which can retain higher coherency due to its relatively long wavelength $(23.8 \mathrm{~cm})$ and allows us to examine detailed spatiotemporal changes in glacier velocities. The observed velocity variability will also be used as a reference dataset to diagnose if any episodes such as active surging and/or pulse event are ongoing.

\section{STUDY AREA}

We focus on five glaciers in the Eastern Karakoram Range: the Baltoro, Siachen, Kundos, Gasherbrum and Singkhu Glaciers (Fig. 1). The relatively large size of these glaciers allows us to derive a detailed surface velocity distribution under the available spatial resolution of ALOS-1/2 images.

With a length of $\sim 58 \mathrm{~km}$, the Baltoro Glacier is one of the longest glaciers in the Karakoram Range (Copland and others, 2009). It is mostly debris-free in its upper reaches, but its debris cover becomes thick and extensive near its terminus (Quincey and others, 2009). Using ASTER imagery and GPS data, the lower most $13 \mathrm{~km}$ of the Baltoro Glacier were also examined for surface velocity (Copland and others, 2009).

The Siachen Glacier is $\sim 72 \mathrm{~km}$, the longest in the study area. Rankl and others (2014) have derived velocity data over Siachen Glacier, but a detailed spatial and temporal evolution of the glacier's velocity has remained elusive. Using multi-satellite images, Agarwal and others (2017) examined changes in its area, elevation, mass budget and velocity. The velocity data were, however, limited to one summer pair in 2007 and one winter pair from December 2008 to January 2009, with detailed temporal changes being uncertain.

The Kundos Glacier has two tributaries, with the eastern being $\sim 5 \mathrm{~km}$ longer than the western (Figs 1, 2c). Whereas the Kundos Glacier surface velocity was mapped by Rankl and others (2014), only one snapshot was given, and its spatiotemporal evolution remains uncertain.

For the Gasherbrum Glacier, a surge has been reported (Mayer and others, 2011; Quincey and others, 2011). We derive the surface velocity evolution during the transition period from the active phase to the quiescent phase, and complement previous findings on the surge dynamics.

The Singkhu Glacier is smaller than the Baltoro, Siachen and Kudos glaciers, and is located at altitudes between 4500 and $5800 \mathrm{~m}$ a.s.l. Its seasonal and interannual velocity variability has not been reported before.

\section{MATERIAL AND METHODS}

The processing method closely follows that of previous studies (Strozzi and others, 2002; Yasuda and Furuya, 2013; Abe and Furuya, 2015). The pixel-offset (feature/ speckle) tracking algorithms are based on maximizing the cross-correlation of intensity image patches. The Gamma software package was used to process the SAR dataset (Wegmüller and Werner, 1997). For the ALOS-1 dataset, we use the fine beam single/dual (FBS/FBD) mode images along the ascending path. Their incidence angle at the center of the image is $38.7^{\circ}$, varying only $\sim 4^{\circ}$ from the near range to far range. The FBD data were oversampled in the range direction. The temporal baseline for ALOS-1 varies from 46 to $184 \mathrm{~d}$, while for ALOS-2 it varies from 28 to $196 \mathrm{~d}$ (Table 1). For the ALOS-2 data, we use strip mode (SM3) imagery along the ascending path. In ALOS-1 data, Baltoro Glacier was covered by path 524 , and the remaining glaciers were studied by using the data along path 523. In ALOS-2 data, the downstream area (from the terminus to $\sim 25 \mathrm{~km}$ ) of Baltoro Glacier was covered by the rightlooking fine-beam mode (RLF2_5, with an incidence angle of $31.4^{\circ}$ ), whereas the $\sim 25-49 \mathrm{~km}$ point of Baltoro and all of the other glaciers were analyzed by using data along the RLF2_6 mode with an incidence angle of $36.3^{\circ}$. The spatial coverage of each satellite is shown in Figure 1.

To establish the best processing parameters, we selected the image pairs by considering two major factors. First, as the possibility of surface-feature preservation is high in winter, we selected pairs in the winter span (December to March). Second, pairs were selected with the shortest possible temporal baseline (46 d for ALOS-1; 28 and $70 \mathrm{~d}$ for ALOS-2 data) (Table 1). While various possibilities of search patch size and sampling interval were tested, the velocity has been derived with a search patch of $128 \times 128$ pixels (range $\times$ azimuth), with a sampling interval of $12 \times$ 36 pixels. We set 3.0 as the threshold of the signal-to-noise ratio. The patches below this level were treated as missing data. The separation between satellite orbit paths and the effect of foreshortening over rugged terrain produces a stereoscopic effect known as an artifact offset (Strozzi and others, 2002; Kobayashi and others, 2009), which was corrected during the pixel-offset tracking with the use of the elevation-dependent correction. For the DEM, we used the Advanced Space-borne Thermal Emission and Reflection 


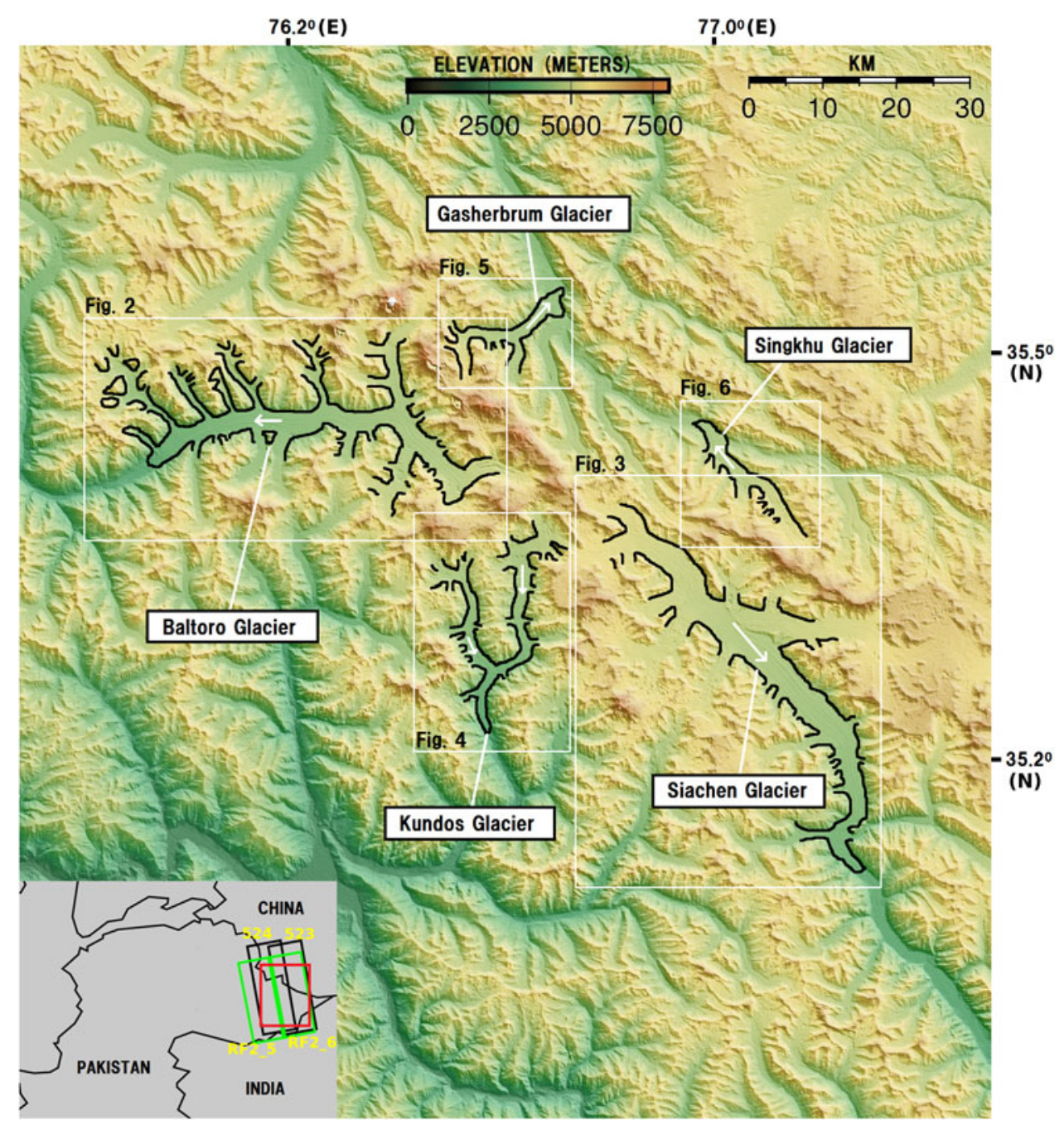

Fig. 1. Location of the studied glaciers. Spatial-temporal evolution of surface velocities at each glacier is shown separately in Figures $2-6$ and in Supplementary materials file (Figs S1-S5). The spatial extent of the overview maps provided in Figures $2-6$ are indicated by white rectangles. The ASTER-GDEM was used as a source of elevation in the background. Inset: black and green rectangles show ALOS-1/ PALSAR-1 observation paths $(523,524)$ and ALOS-2/PALSAR-2 look IDs (RF2_5 = RLF2_5, RF2_6 = RLF2_6), respectively.

Radiometer (ASTER) global digital elevation model (GDEM) Version 2 (https://gdex.cr.usgs.gov/gdex/).

The velocity was calculated by following the parallel flow assumption (Joughin and others, 1998). The ASTER-GDEM was used to calculate the local topographic gradient unit vector. The detailed surface velocity field of each glacier is given in the Supplementary materials file. To examine the spatial and temporal changes in velocity, we first determined the flowline at each glacier and then averaged the velocity data over the $200 \mathrm{~m} \times 200 \mathrm{~m}$ area with its center at each flowline. The velocity errors were estimated by measuring the offsets on stable ground (non-glaciated area) (Pritchard and others, 2005; Yasuda and Furuya, 2013; Abe and Furuya, 2015), and they are $12-17 \mathrm{~m} \mathrm{a}^{-1}$ for ALOS-1 data and $20-30 \mathrm{~m} \mathrm{a}^{-1}$ for ALOS-2 data. Furthermore, we have divided the Baltoro and Siachen Glaciers into four regions: three regions of the main glacial channel (upstream, central and terminal areas) plus the major tributary (e.g. GodwinAusten for the Baltoro, Teram Shehr for the Siachen). The lengths of the subregions vary for each glacier, and the start and end of a region were set where we found some notable changes in velocity. This subdivision has not been done for the other three glaciers as there were no such notable changes in velocity along their length.
Pixel-offset tracking by L-band SAR is known to often generate 'azimuth streaks' (Gray and Mattar, 2000; Kobayashi and others, 2009). In our ALOS-1/2 data, we observed the streaking pattern in many pairs of ALOS-2 but in few of ALOS- 1 . This is presumably because for ALOS-2, the data acquisition time is mostly in the local daytime, when there is a higher chance of irregularities in the ionosphere due to the higher background total electron content. Moreover, the streaking is more likely to appear in the data collected close to or in the polar regions (Gray and Mattar, 2000). Furthermore, the amplitude of glacier displacement is essentially proportional to the temporal period between master and slave date, whereas the amplitude of azimuth streaks arises as a snapshot at the time of imaging. The observed glacier velocities are on the order of $100 \mathrm{~m} \mathrm{a}^{-1}$ or more, and as such, the 'azimuth streaks' did not substantially affect the observed velocity, and are within the errors of the observed velocities. But these streaks are possibly the main reason that ALOS-2 has more error in velocity than ALOS-1.

The ice penetration depth of L-band microwave is $\sim 15 \mathrm{~m}$ (Rignot and others, 2001). Here we assume uniform velocity through the ice layer near the surface down to this penetration depth. 
Table 1. ALOS-1/2 data used in this research. Bold areas show the reference pairs for which various feature tracking parameters are tested (YYYYMMDD)

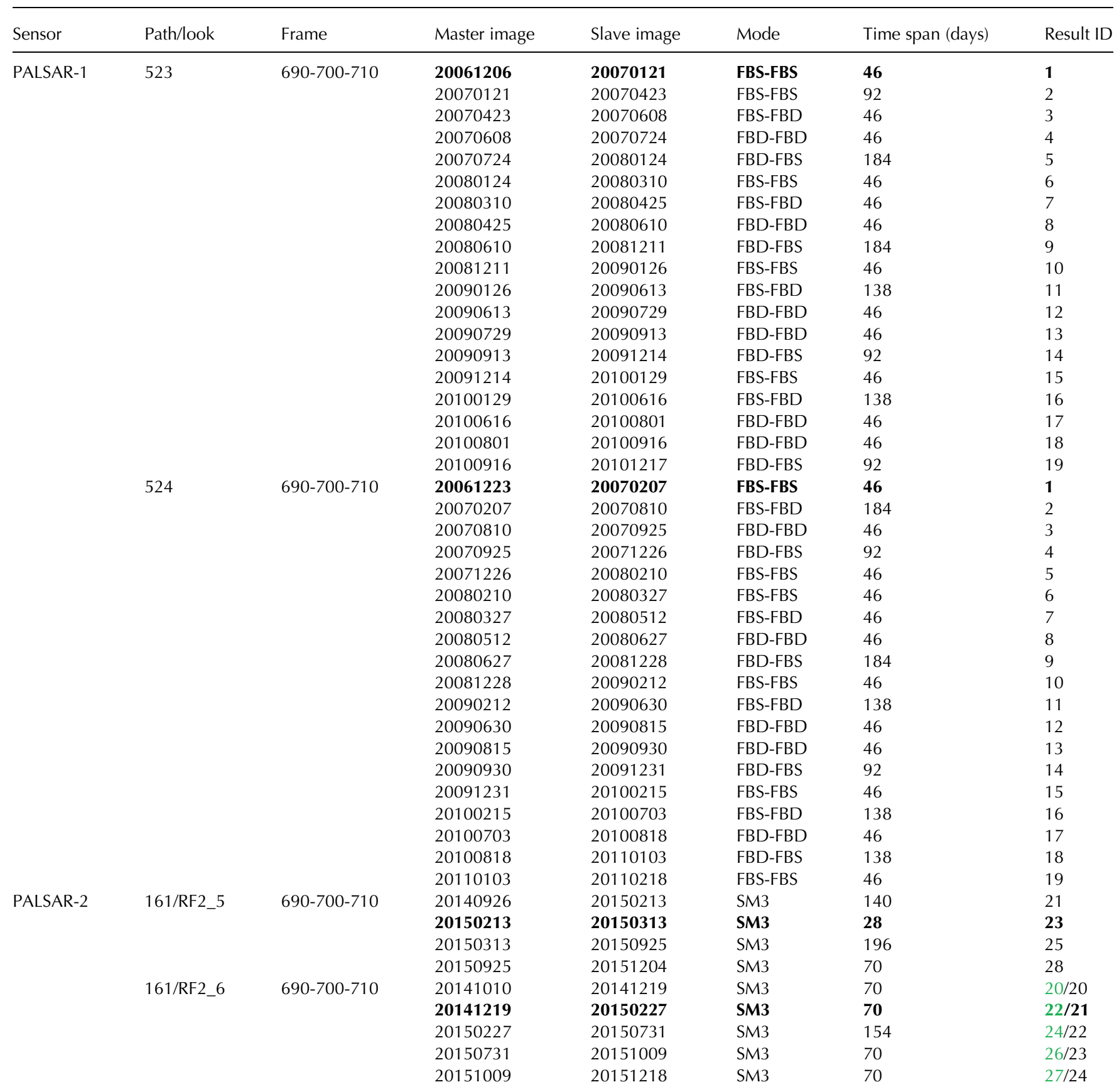

Result ID column: green numbers indicate the pair IDs covering the upstream part of the Baltoro glacier and Godwin-Austen tributary. For the path 523 (covering Siachen, Kundos, Gasherbrum and Singkhu Glaciers), the count for ALOS-2 data continues for RLF2_6 only. For the path 524 (covering Baltoro Glacier), both the look angles (RLF2_5 and RLF2_6) cover the glacier and the count is indicated with black and green numbers.

\section{RESULTS}

\subsection{Baltoro Glacier}

Of the five glaciers, the Baltoro is the only glacier whose detailed velocity evolution has been extensively studied (Quincey and others, 2009). About $35 \mathrm{~km}$ from its terminus lies Concordia, where the Godwin Austen Glacier comes down from the north and joins the main channel of Baltoro Glacier. The maximum velocity of $\sim 180 \mathrm{~m} \mathrm{a}^{-1}$ occurs just downstream of Concordia and from here the velocity gradually decreases downstream until the terminus (Fig. 3a). To examine the details, we divided the entire glacier into four regions from upstream to downstream (including the
Godwin-Austen), and show the velocity evolution of each region separately (Figs 3b, e).

These spatial velocity patterns are mostly consistent with those observed by Quincey and others (2009), although some changes occurred after 2008. The summer speed-up signals are clear every year (Fig. 3a), but are more distinct in the downstream region. For example, the GodwinAusten Glacier shows no significant summer speed-up signal except for the 2008 summer in its upstream part (Fig. 3e). As Quincey and others (2009) found for 2005, we see an extra speed-up in 2008, especially in the 10-35 km region (Figs 3a, c, d). However, Quincey and others (2009) found that the terminal region $(0-16 \mathrm{~km})$ did not show 

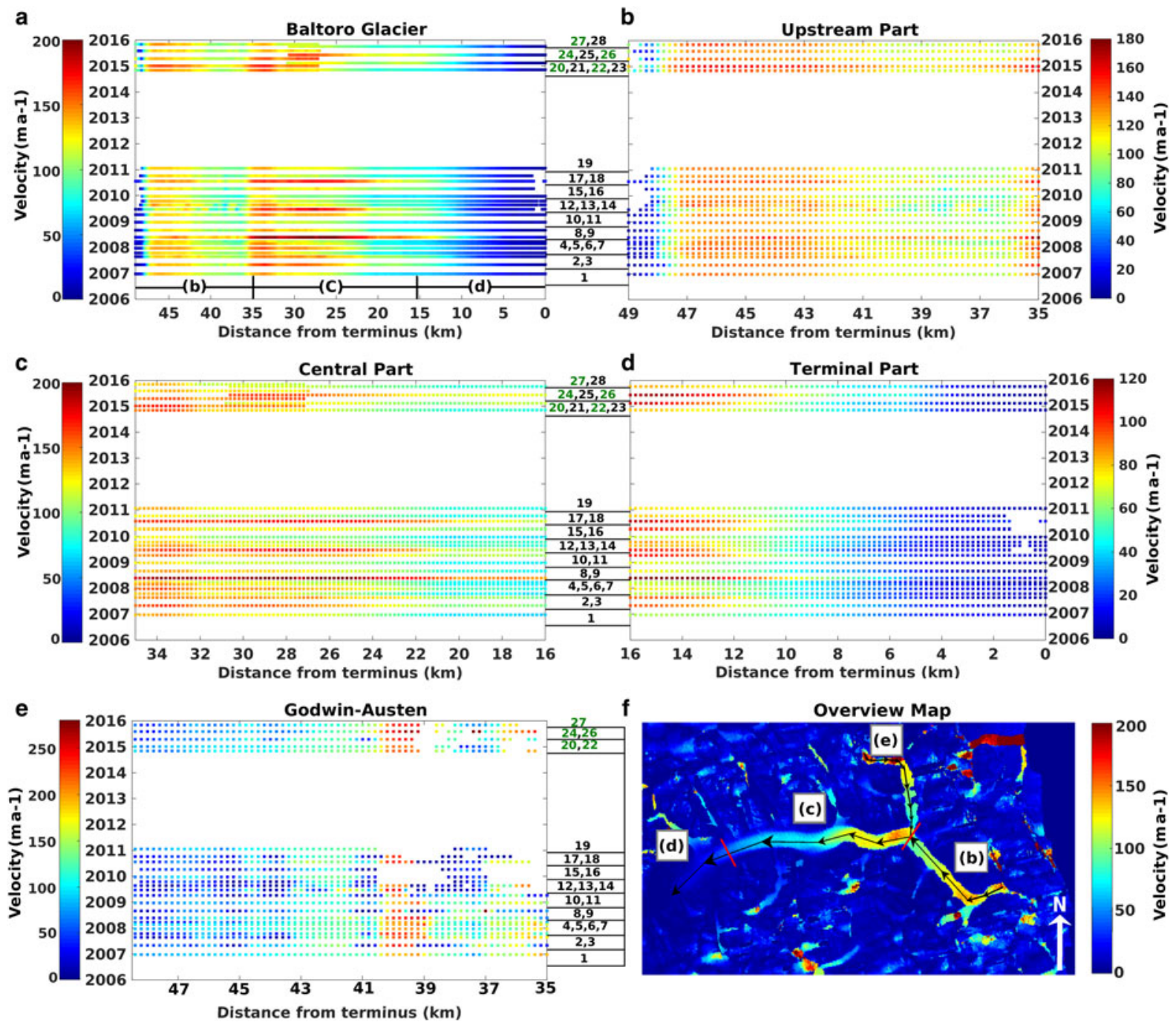

Fig. 2. (a) Spatial and temporal surface velocity changes extracted along the entire length of the centerline of the Baltoro Glacier. Expanded view of individual centerline segments of Baltoro Glacier; (b) upstream portion (49-35 km), (c) central portion (35-16 km), (d) terminal potion $(16-0 \mathrm{~km})$ and $(\mathrm{e})$ the Godwin-Austen tributary (red lines indicate the boundary of each segmented centerline portion). The color scale in (a, b, $c, d, e, f)$ indicates the scale for the velocity of the glacier, its various parts and of the overview map. The numbers between the color scales and velocity figures indicate the time in years, and they are labeled at the start of the year, i.e. January. The numbers between the vertical axes of the velocity figures, i.e. between (a) and (b), (c) and (d) and on the right side of figure (e) indicate the corresponding analyzed pair results of master-slave images. The detail of the respective pair dates are given in Table 1 and the corresponding velocity field of each pair are given in Figure S1. The green numbers indicate the master-slave images of beam having the right-looking fine-beam mode (RLF2_6). (f) Surface velocity snapshot of Baltoro Glacier derived from 23 December 2006 and 7 February 2007 data. The black line shows the profile line along which the velocity was calculated and arrows indicate the flow direction of the glacier.

significant changes in speed over the period 1992-2008. Except for the lowermost $\sim 5 \mathrm{~km}$, we observe a clear summer speed-up that is extended from the central region (Fig. 3d) in the ALOS-2 data.

Quincey and others (2009) observed faster speeds in the winter of 2007/2008. Using ALOS1/2 data, we also detected faster winter speeds in the same year (Fig. 3c) as well as in 2014/2015 (Figs 3b, c). However, the speeds are lower in 2008/2009 and 2009/2010. We can observe similar velocity changes in the Godwin-Austen Glacier, indicating faster speeds in the 2007/2008 and 2014/2015 winter seasons (Fig. 3e).

\subsection{Siachen Glacier}

The velocity along the flowline of the Siachen Glacier decreases gradually from the upstream to the central region and reaches its maximum value between 30 and 40 $\mathrm{km}$ upstream from the terminus (Fig. 4a). In this region, we find clear seasonal and interannual variability. Below the $30 \mathrm{~km}$ point, the velocity steadily drops until the terminus of the glacier. The small velocity increases at 12 and $20 \mathrm{~km}$ probably arise from the tributaries. We again divide the entire glacier into four regions and show the velocity evolution with a different color scale for each part (Figs $4 \mathrm{~b}-\mathrm{e}$ ).

After 2014, the summer speeds over both the central and upstream regions appear slower than in the previous years (Figs 4a, c). For example, the 2015 summer speed in the central part is below $200 \mathrm{~m} \mathrm{a}^{-1}$ and the upstream winter speed is slower than the previous year's by more than $35 \%$. The presence of seasonality in the upstream region is not clear because it often undergoes a decorrelation problem. This problem occurs because the summer snowfall at higher elevations can significantly change the surface features, creating difficulty for the offset-tracking algorithm, and thus making it difficult to measure the velocity (Figs $4 a, b$ ). 

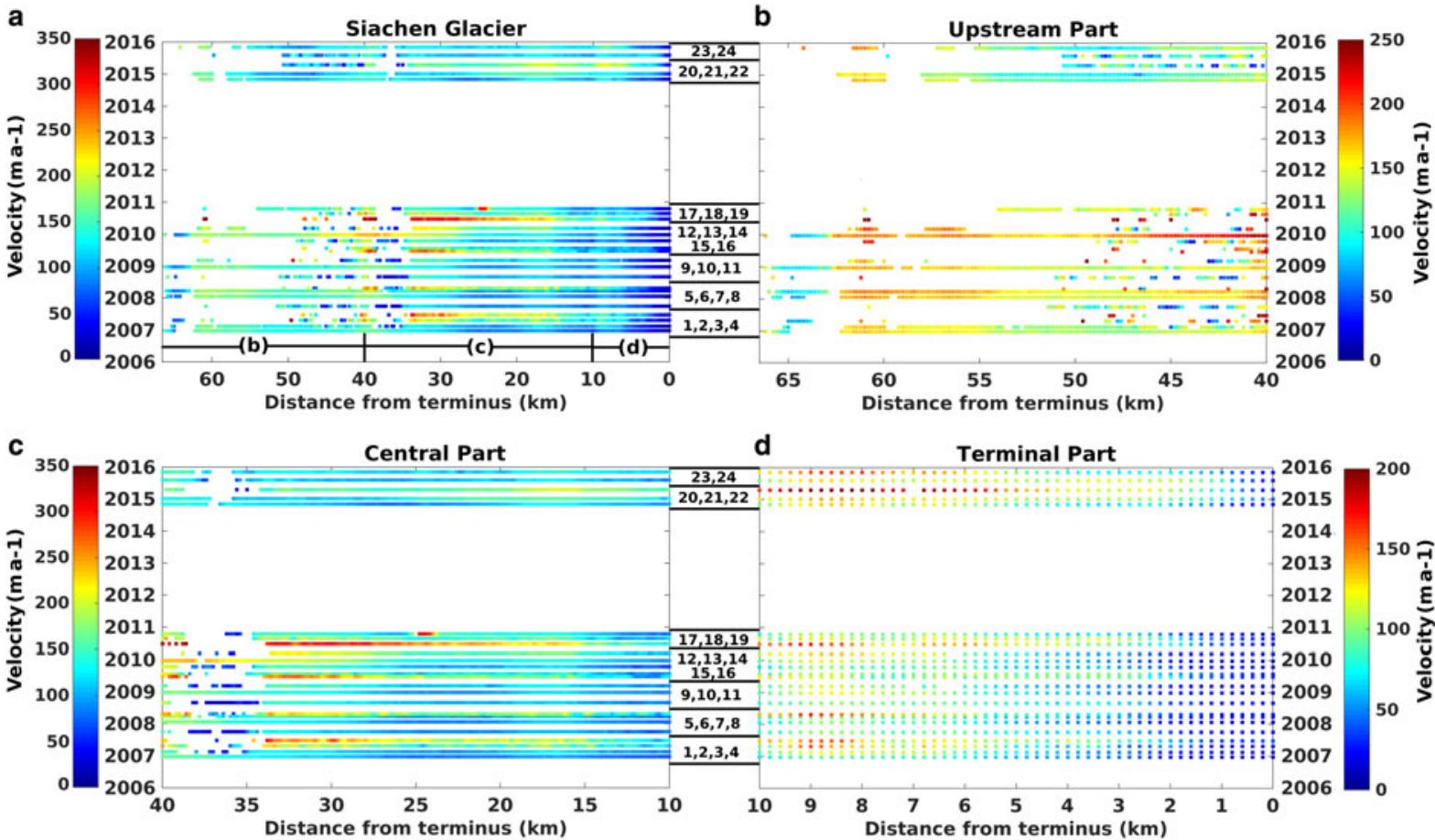

d Terminal Part
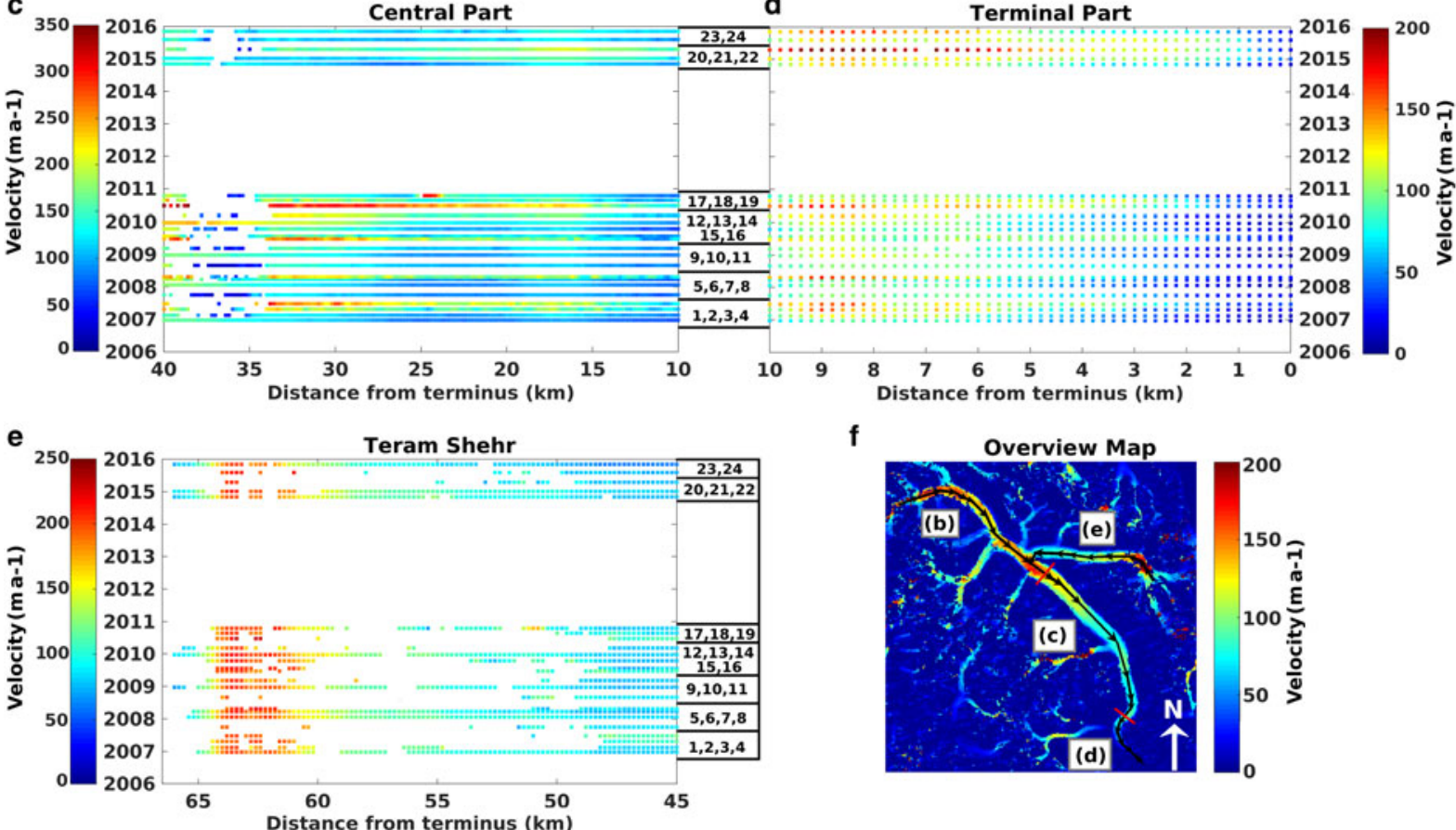

f

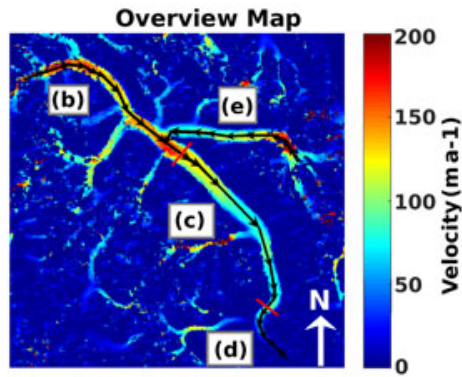

Fig. 3. (a) Spatial and temporal surface velocity changes extracted along the entire length of the centerline of the Siachen Glacier. Expanded view of individual centerline segments of Siachen Glacier; (b) upstream portion (66-40 km), (c) central portion (40-10 km), (d) terminal potion $(10-0 \mathrm{~km})$ and $(\mathrm{e})$ the Teram Shehr tributary (red lines indicate the boundary of each segmented centerline portion). The color scale in (a, b, c, $\mathrm{d}, \mathrm{e}, \mathrm{f}$ ) indicates the scale for the velocity of the glacier, its various parts and of the overview map. The numbers between the color scales and velocity figures indicate the time in years, and they are labeled at the start of the year, i.e. January. The numbers between the vertical axes of the velocity figures, i.e. between (a) and (b), (c) and (d) and on the right side of figure (e), indicate the corresponding analyzed pair results of master-slave images. The details of the respective pair dates are given in Table 1 and the corresponding velocity field of each pair is given in Figure S2. (f) Surface velocity snapshot of Siachen Glacier derived from 6 December 2006 and 21 January 2007 data. The black line shows the profile line along which the velocity was calculated and arrows indicate the flow direction of the glacier.

Nevertheless, in the 2009/2010 winter season, the results show a significant speed-up upstream, being nearly twice as high as all other years (Fig. 4b), and also show a speedup over the central part (Fig. 4c). In contrast, the terminal region has its fastest speed in the 2015 summer, being 30\% faster than the 2010 summer when the maximum speed occurs in the central part.

In contrast, Siachen Glacier's largest tributary, the Teram Shehr Glacier, shows very little interannual speed variations over the last 10 years (Fig. 4e). This nearly steady velocity distribution demonstrates that the observed velocity changes in the main trunk are not an artifact of the change of satellite from ALOS-1 to ALOS-2.

\subsection{Kundos Glacier}

The Kundos Glacier has two tributaries. In the western tributary, the speed gradually decreases from the upstream region until the $23 \mathrm{~km}$ location (Fig. 2a), which is at the confluence of upstream tributaries. Then, between 23 and $18 \mathrm{~km}$, the speed increases, and downstream from this, it gradually decreases. Upon passing another confluence $\sim 14 \mathrm{~km}$, it flows faster until about $9 \mathrm{~km}$. After this zone, the speed decreases to the terminus. Thus, there are three segments of velocity pattern that are mostly controlled by incoming flow from tributaries (c.f. Bhambri and others, 2017; Jiskoot and others, 2017).

The velocity distributions of the eastern tributary are also segmented (Fig. 2b) and controlled by the presence of tributaries. The velocity has a maximum near the $30 \mathrm{~km}$ point, which is just below a confluence, then slowly decreases southward. A final increase occurs near $9 \mathrm{~km}$ at the main confluence of eastern and western tributaries (Fig. 2b). Below this point, most of the ice flow comes from the western tributary, with the western tributary preventing the inflow from the eastern tributary. Thus, the speed decreases 


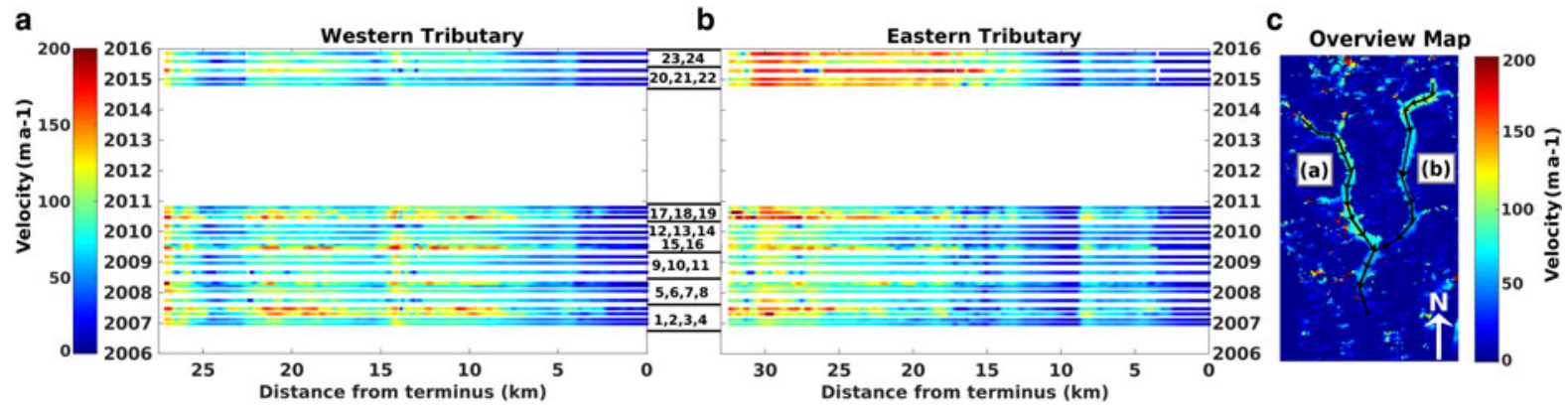

Fig. 4. Spatial and temporal surface velocity changes extracted from the centerline of the (a) western tributary and (b) eastern tributary of Kundos Glacier. (c) Surface velocity snapshot of Kundos Glacier derived from 6 December 2006 and 21 January 2007 data. The black line is a profile line along which the velocity was calculated and arrows indicate the flow direction of the glaciers. After the confluence, i. e. about the 0-9 km area of (a, b), the velocity was calculated along the same line for both parts. The color scale in (a, b) indicates the scale for the velocity of the glacier. The same scale has been used for the overview map as well. The numbers between the color scales and velocity figures indicate the time in years, and they are labeled at the start of the year, i.e. January. The numbers between the vertical axes of the velocity in $(a, b)$ indicate the corresponding analyzed pair results of master-slave images. The details of the respective pair dates are given in Table 1 and the corresponding velocity field of each pair is given in Figure S3.

to about zero at $9 \mathrm{~km}$, and then abruptly jumps to the value for the western flowline. After this, both flowlines have the same speed.

Concerning seasonal changes, both tributaries clearly show higher velocities in summer, although the amplitude of peak summer velocity is highly variable. For example, in the western tributary, the summer speeds in 2008 and 2015 are $<120 \mathrm{~m} \mathrm{a}^{-1}$, whereas those in other years are $>150 \mathrm{~m} \mathrm{a}^{-1}$ (Fig. 2a). In the eastern tributary (Fig. 2b), the maximum summer speed is $100 \mathrm{~m} \mathrm{a}^{-1}$ in 2008 , but $\sim 60 \%$ faster in the summer of 2010 and over $80 \%$ faster in 2015 (even over the 15-25 km portion, where no summer speedup has been observed previously).

Since 2014, a higher velocity has been detected in the upstream part of the eastern tributary, regardless of the season. The 2014/2015 and 2015/2016 winter speeds are clearly faster by $30 \%$ or more than those in previous winter seasons.

\subsection{Gasherbrum Glacier}

Gasherbrum Glacier underwent a surge that started in fall 2005 and reached its peak velocity of $500 \mathrm{~m} \mathrm{a}^{-1}$ during the summer of 2006 (Mayer and others, 2011; Quincey and others, 2011), and is now apparently in its quiescent phase (Fig. 5). Accordingly, the velocity steadily decreases from its upstream region to the terminus. Our data were collected since 2007, and complements the previous studies, showing the transition from the active phase to the quiescent phase in finer detail.

We observe a slowdown in the winter of 2006/2007, but then a significant acceleration in the summer of 2007, again reaching a velocity of $500 \mathrm{~m} \mathrm{a}^{-1}$ (Fig. 5a). The latter peak speed was not reported in Quincey and others (2011), and indicates that peak velocities occurred both in the summers of 2006 and 2007. In the fall of 2007, the speed decreased to about $250 \mathrm{~m} \mathrm{a}^{-1}$, which is consistent with the previous studies (Mayer and others, 2011; Quincey and others 2011). After the active phase, the glacier becomes nearly stagnant in the lower $\sim 10 \mathrm{~km}$ portion. Nonetheless, this glacier showed a summer speed-up in 2008 (Fig. 5a). However, the amplitude and spatial extent of the summer speed-up seem to have decreased since 2008.

\subsection{Singkhu Glacier}

Singkhu Glacier, at an elevation of $4500-5800 \mathrm{~m}$ a.s.l., is both relatively high and relatively short compared with the other glaciers. Due to its colder climate, the glacier may be less likely to have short-term velocity changes. However, our measurements show clear summer speed-up signals with interannual modulations, with the fastest speed occurring in the 2010 summer (Fig. 6a). In fact, there are two zones of faster summer velocity, one at 11-14 km and one at 3-10 km. As observed with Kundos Glacier, these two distinct velocity distributions are presumably due to confluences with a major tributary glacier.

As we found for the Siachen Glacier, we were not able to derive the upstream velocity in the summer season, which is probably due to the lower image correlation caused by snow accumulation in summer. In 2014-2015, however, we do not observe clear seasonal changes as observed previously, and the maximum summer speed declines, which agrees with that found for the Siachen and western tributary of the Kundos Glacier.

\section{DISCUSSION}

\subsection{Interglacial spatiotemporal velocity variability at seasonal and interannual scales}

Our derived velocity data show that both the amplitude and spatial extent of summer speed-up vary from year to glacier. For example, not all the glaciers have their maximum summer velocity in the same year. Moreover, maximum speeds within the same glaciers vary from year to year, which presumably indicates the variability of basal sliding, which is controlled by basal water pressure that depends not only on the input volume of surface meltwater, but also on the capacity of the subglacial hydraulic system at each individual glacier.

Concerning the larger summer speed-ups, Quincey and others (2009) found an anomalously fast summer speed-up in 2005 at Baltoro Glacier, which was interpreted to indicate additional basal sliding due to the larger volumes of meltwater made available by the deep snowpack in the preceding winter. We found two notable summer speed-ups: one in 2008 at Baltoro Glacier and one in 2010 in the central part of Siachen Glacier. Moreover, we found additional summer 


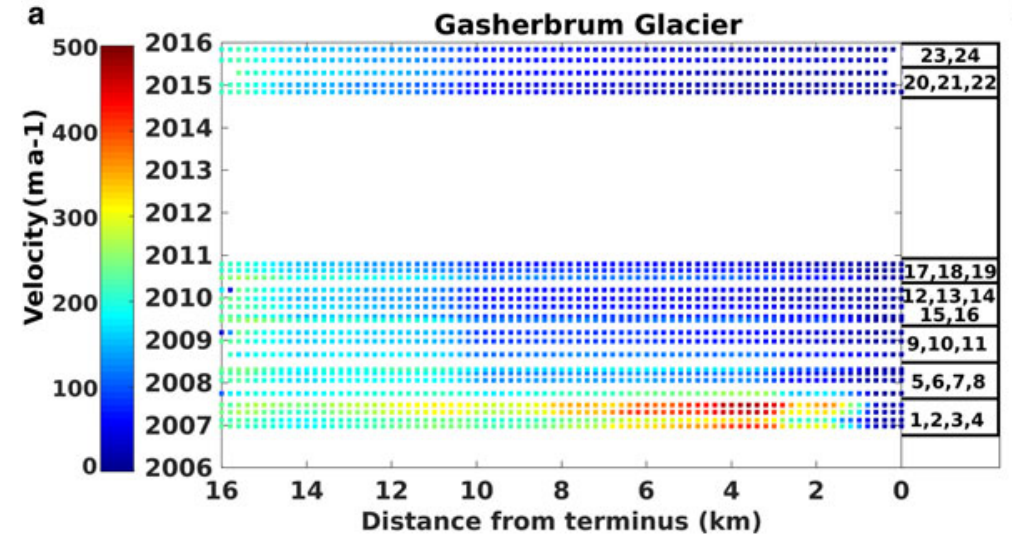

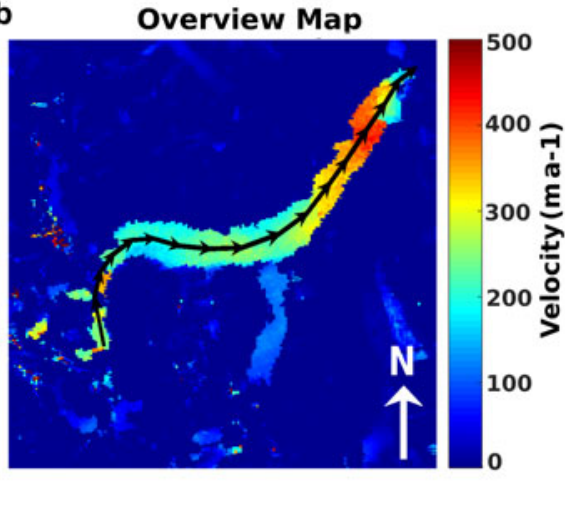

Fig. 5. (a) Spatial and temporal surface velocity changes extracted from the centerline of Gasherbrum glacier. The color scale indicates the scale for the velocity of the glacier. The same scale has been used for the overview map as well. The numbers between the color scale and velocity figure indicate the time in years, and they are labeled at the start of the year, i.e. January. (b) Surface velocity snapshot of Gasherbrum Glacier derived from 6 December 2006 and 21 January 2007 data. The black line is the profile line along which the velocity was calculated and arrows indicate the glacier's flow direction. The numbers at the right side of figure (a) indicate the corresponding analyzed pair of masterslave images. The details of the respective pair dates are provided in Table 1 and the corresponding velocity field of each pair is given in Figure S4.
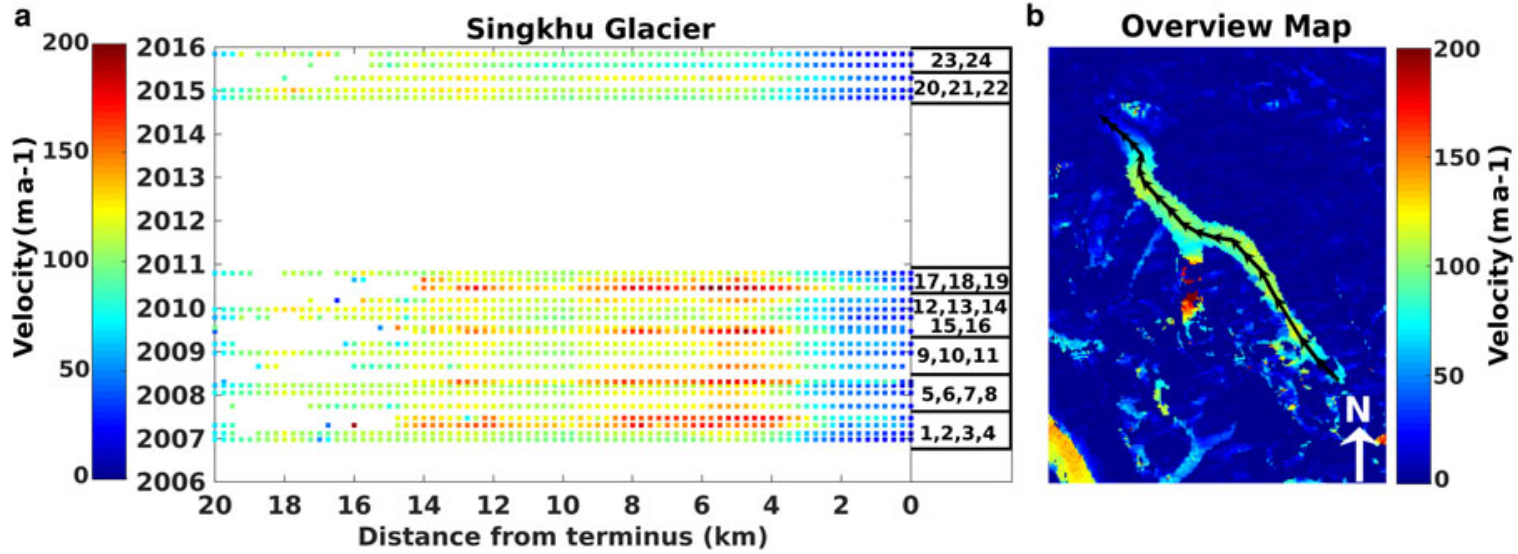

Fig. 6. (a) Spatial and temporal surface velocity changes extracted from the centerline of Singkhu Glacier. The color scale indicates the scale for the velocity of the glacier. The same scale has been used for the overview map as well. The numbers between the color scale and velocity figure indicate the time in years, and they are labeled at the start of the year, i.e. January. (b) Surface velocity snapshot of Singkhu Glacier derived from 6 December 2006 and 21 January 2007 data. The black line is the profile line along which the velocity was calculated and arrows indicate the glacier's flow direction. The numbers at the right side of figure (a) indicate the corresponding analyzed pair of masterslave images. The details of the respective pair dates are provided in Table 1 and the corresponding velocity field of each pair is given in Figure S5.

speed-up signals, such as on the terminal part of Siachen in 2015 and on the eastern tributary of Kundos in 2015.

All summer speed-ups may be due to a large-volume surface meltwater pulse each spring or summer (c.f. Müller and Iken, 1973; Iken and Bindschadler, 1986). However, this argument is implicitly based on two arguable assumptions: (1) the large surface meltwater pulse is limited to each local glacier at different times, and (2) surface meltwater can efficiently reach the bed and broadly increase basal water pressure during the corresponding same summer.

For the first assumption, we should consider the possibility of heterogeneous climate over the studied area. For such analyses, as surface meteorological data are probably infeasible, one may need to run downscaling analysis of large-scale global numerical weather data (e.g. Bieniek and others, 2016), considering the complex topography and large elevation differences that can affect the surface weather conditions. However, for the Kundos Glacier, where the close proximity of its tributaries suggests similar surface meteorological conditions, we found that the extra summer speedup occurred only in the eastern tributary in 2010 and 2015, whereas the western tributary has slowed down since 2015. Instead, the eastern tributary's 2015 speed-up may be a sign of surge initiation, which we will discuss in more detail below. This case suggests that the external meteorological forcing at each glacier does not directly control the summer speed in the same year.

For the second assumption, an efficient passage of meltwater may not be necessary. For example, the summer velocity increases in 2008 at Baltoro, 2010 at Siachen and 2015 at the eastern tributary of Kundos Glaciers were all preceded by relatively fast speeds in the previous winter in their upper regions (Figs 2b, 3b, c, 4b, c). These observations indicate that the extra basal sliding does not necessarily start in the summer, but instead already during the preceding winter in the upstream regions. Although the cause of this 
upstream speed-up is unclear, once the speed-up occurs, it could help surface meltwater in the following summer to more broadly increase the basal water pressure over the entire glacier. For example, the winter increase in basal sliding would generate more space on the leeward side of bedrock bumps (Kamb, 1987; Schoof, 2010), making the basal water cavities more widely connected when large volumes of meltwater become available in spring to early summer (Iken and Truffer, 1997).

The question that follows is how the upstream speed-up can be initiated in winter. The winter speed-up in the upstream that precedes a larger summer speed-up is only observed once every several years. The interim time period may be a 'recharge time' for the upstream subglacial hydraulic system to generate higher basal water pressure. Unlike the downstream ablation zone, the upstream region generally does not have high volumes of surface meltwater input every summer, and thus it would take longer time to store basal water by either pressure melting of ice like the Svalbard-type thermal regulation (e.g. Murray and others, 2003) or interstitial englacial water generated by strain heating (Aschwanden and Blatter, 2005) and their gravitydriven movement as suggested by Irvine-Fynn and others (2006). Although ice creep will generate locally isolated cavities with high-pressure water, the extra speed-up in winter requires that those cavities become broadly connected, which would also take over 1 year. In this way, the 'recharge time' for the upstream winter speed-up would be several years, ultimately leading to the larger summer speeds every several years. The extra summer speed-up preceded by upstream winter speed-up might be better viewed as 'surge-like' events reported by Bhambri and others (2017).

The recent decrease in summer flow speed at Siachen, the western tributary of Kundos and the Singkhu Glaciers may have occurred because the basal hydraulic system has become more efficient, perhaps due to a long-term larger influx of meltwater reducing the basal water pressure. At the Godwin-Austen Glacier, the absence of a summer speed-up may indicate that either no meltwater could reach the base of glacier (e.g. due to colder ice in the upstream region) or that the morphology of the underlying bed is such that the summer melt does not have an impact on the ice motion.

\subsection{Role of hydrological and thermal control mechanisms for flow instability in the Karakoram Range}

Surge-type glaciers dominate the Karakoram Range (e.g. Hewitt, 1969, 2007, 2011), but their generation mechanism remains uncertain (e.g. Harrison and Post, 2003; Jiskoot, 2011; Sevestre and Benn, 2015).

To explain differences in surge behavior, Murray and others (2003) proposed the Alaskan-type hydrological-regulation and Svalbard-type thermal-regulation mechanisms for the generation of high-pressure basal water that could drive an active surge. In a thermally controlled surge, the initiation and termination phases last for several years before and after the peak phase, respectively, with all phases being independent of the season (Jiskoot, 2011). On the other hand, hydrologically driven surges are characterized by a rapid acceleration and deceleration, and have a tendency to initiate in winter (Raymond, 1987; Harrison and Post, 2003) and terminate in summer (Björnsson, 1998).
The two models are also entirely different in terms of the origin of basal water. In the hydrological model, the water mainly originates from surface melt, while in the thermalregulation model, it is generated by pressure melting and frictional heating by the accelerated basal motion without input of surface meltwater. Recent observations, however, suggest that any of these mechanisms cannot be generalized to a study area containing multiple surge-type glaciers (Jiskoot and Juhlin, 2009; Quincey and others, 2015).

For the Karakoram, Quincey and others (2015) proposed that the surges are part of spectrum from normal slow flow to permanent fast flow, governed by hydrological and basal thermal processes. Moreover, Paul (2015) and Bhambri and others (2017) argued that Karakoram glacier surges are only marginally affected by external climate forcing. We find similar behavior in our study area. In particular, Siachen and the eastern tributary of Kundos have shown surge/minisurge initiation signals independently from each other, indicating that these events are probably not controlled by climate forcing, but rather are the result of internal mechanisms of the glaciers (Raymond, 1987; Jiskoot, 2011).

Of the five glaciers examined in this study, only Gasherbrum Glacier was surging, and in transition to its quiescent phase. In combination with the previous studies that covered this glacier's earlier phases (Quincey and others, 2011; Mayer and others, 2011), we find that the surface velocities during the active phase turn out to be seasonally modulated with their peak flow in summer. This observation may have an important implication for the Karakoram surge mechanism, particularly because similar seasonal modulation during the active phase has also been found at two glaciers in West Kunlun Shan, northwestern Tibet (Yasuda and Furuya, 2015) and at Hispar Glacier in central Karakoram (Paul and others, 2017). In particular, we consider that the seasonal modulation of the peak velocity amplitude is a possible evidence for the role of surface meltwater input to maintain the active phase of polythermal surge-type glaciers; polythermal structure has been assumed by Quincey and others (2015) too. As observed in Karakoram glaciers by Bhambri and others (2017), an active surge could generate surface crevasse probably due to the increased longitudinal extensional stress over the glacier through which surface meltwater could easily reach the glacier bed and thereby further enhance the basal water pressure. This process would then help maintain the seasonally modulated active phase. Although it was not a seasonal modulation, Sund and others (2014) suggested a similar process for the surge development at the polythermal surge event of Nathorstbreen glacier system, Svalbard.

For Siachen Glacier, the faster flow region initiated in the upstream part of the glacier in early 2010 may have propagated downstream. Although it is not a surge, this is reminiscent of a 'mini-surge' or 'glacier pulse' observed in Alaskan glaciers (Kamb and others, 1985) and Karakoram glaciers (Bhambri and others, 2017), or an incomplete surge development as observed for Svalbard glaciers (Sund and others, 2009). Because no other examined glaciers revealed similar acceleration in 2010, it is probably not due to any anomalous external climate forcing in 2010, but rather due to local and internal mechanisms at the glacier.

The eastern tributary of Kundos Glacier may have started to surge recently (Fig. 2b). Acceleration occurred in the winter before the maximum speed in the summer of 2015, and this was followed by a velocity decline in the fall of 
2015, and another acceleration in the winter of 2015. Even though it may not be a surging episode, the behavior is similar to the surge velocity behavior of Hispar Glacier in the Karakoram, where Paul and others (2017) also noticed a rapid decline in velocity immediately after the maximum speed event in the summer of 2015, with the velocities again increasing significantly in winter 2015-2016 (i.e. after the sudden velocity decline). As Paul and others (2017) suggested for the Hispar Glacier surge, the recent speed-up data at the eastern tributary of Kundos Glacier seems to conform to the Alaskan-type glacial surge model.

Particularly for Alaskan glacier surges, it is known that active phase often initiates in winter (Raymond, 1987). Although there are few reliable reports in Karakoram, Bhambri and others (2017) also mentioned a couple of active surges initiated in winter. Furthermore, all the minisurge events in our study area start in winter as we discussed in the previous section. As winter should have a less efficient basal-drainage system that can more easily generate higher basal water pressure, the initiation in winter may involve subglacial water pooling over a multi-year period due to a combination of basal pressure melting, geothermal heat flux at the bed and/or englacial water storage that can persist over winter (Lingle and Fatland, 2003; Abe and Furuya, 2015).

Although we have separated additional summer speed-up from apparent surging events in this paper, they should lie within the continuous flow-instability spectrum, which much broader than the conventional simple classifications such as 'surge', 'pulse', 'mini-surge' and decadal 'Svalbardtype' (Jiskoot, 2011; Herreid and Truffer, 2016). Our essential argument to include both behaviors in this spectrum is that both events are likely controlled by subglacial and possibly englacial hydrology in the upstream region.

\subsection{Limitations and recommendations}

Our velocity observations demonstrate that the studied Karakoram glaciers are much more dynamically variable in terms of both spatial and temporal evolution than previously reported. Indeed, as our velocity maps are derived from satellite imagery and thus give an average between the acquisition times, the actual velocity changes could be even more dynamic (c.f. Armstrong and others, 2017). However, our study is confined to the surface velocity data only, and we have not considered independent data such as local weather, surface meltwater volume, basal water pressure and basal topography. Thus, the mechanisms we argued here are speculative. Nonetheless, we believe that the observed diverse range of surface velocity variations will have important implications for future studies, not only at glaciers in Karakoram but also other regions in the world.

To prove or reject our hypotheses, we need not only to extend the time coverage of velocity observations, but also to collect local weather data and analyze the spatiotemporal evolution of weather data. Further testing should also involve direct measurements of basal water pressure in the upstream region over several years. Besides the collection of groundbased meteorological and hydrological observations and their comparative analysis with glacier dynamics at selected sites, modeling studies that can couple glacial hydrology with ice dynamics would also be useful. While there are already some pioneering studies that could quantitatively explain the observations at both mountain glaciers and ice sheets (e.g. Kessler and Anderson, 2004; Pimentel and Flowers, 2010; Pimentel and others, 2010; Hewitt, 2013; Hoffman and Price, 2014; Kyrke-Smith and others, 2015; Hoffman and others, 2016), most studies have focused on the summer speed-up signal attributable to the meltwater input in the same year. Any future model that couples subglacial hydrology with ice dynamics may need to include not only the downstream ablation zone, but also the upstream accumulation zone, and to extend the time coverage for the development of the hydrological system from years to decades.

\section{CONCLUSIONS}

We applied offset tracking techniques to most of the available L-band SAR data of ALOS-1/2 to determine the surface-velocity trends of five glaciers in the Eastern Karakoram Range over the period 2007-2015. The glaciers show clear seasonal changes in velocity, but with interannually modulated amplitudes and varied spatial extents. Trends for each glacier appeared independent of the others, indicating that their velocities are probably controlled by local and internal mechanisms. The input from tributaries created upstream bands of lower speed, leading to a segmentation of the velocity trends along the length of the glaciers.

We found that Baltoro Glacier had a velocity increase in the summer of 2008 in its central part and an overall speed-up in its upstream part in 2015-2016, whereas Siachen, Singkhu and the eastern tributary of Kundos Glaciers had a speed-up in the summer of 2010. For Siachen Glacier, the longest tributary, Teram Shehr, had a nearly steady velocity distribution throughout the study period. Since 2014, the western tributary of Kundos Glacier slowed down, while in the eastern tributary speed-up, signals were observed over the upstream part, starting in winter and reaching a peak velocity in the summer of 2015. For Siachen Glacier, the upstream and central parts slowed, while the terminal part had an overall acceleration. On the basis of available data, the velocity changes observed at Siachen and eastern tributary of Kundos Glaciers are interpreted as a mini-surge, suggesting the Alaskan-type surge mechanism. The peak velocities of the Gasherbrum surge were seasonally modulated with two maxima in the summers of 2006 and 2007.

Concerning the mechanisms for flow variability, we argue that the intra/interspatial and temporal changes in englacial/ subglacial system of each glacier may vary the input of surface meltwater to the base and result in diverse velocity patterns in these glaciers. Our surface-velocity findings show intriguing variations, but their temporal resolution and duration are not sufficient to understand the processes of glacier dynamics fully. To more quantitatively interpret the detailed interannual modulation of seasonal velocity variations, we need to acquire regional high-resolution meteorological and hydrological data as well as run numerical modeling that can fully couple ice dynamics with multiyear englacial and subglacial hydrology.

\section{AUTHOR CONTRIBUTIONS}

MU processed, analyzed and produced the results for the ALOS-1/2 data. Both MU and MF have managed the research and drafted this manuscript. Both authors have read and agree with the content of this paper. 


\section{SUPPLEMENTARY MATERIAL}

The supplementary material for this article can be found at https://doi.org/10.1017/jog.2018.39

\section{ACKNOWLEDGEMENTS}

We acknowledge two anonymous reviewers and the Scientific Editor, whose comments were helpful to revise the original manuscript. We are grateful to our colleagues Takatoshi Yasuda and Takahiro Abe for their useful comments. PALSAR-1/2 data were provided by the PALSAR Interferometry Consortium to Study our Evolving Land surface (PIXEL). Ownership of PALSAR-1/2 data belongs to the Japan Aerospace Exploration Agency (JAXA) and the Ministry of Economy, Trade and Industry (METI/Japan).

\section{REFERENCES}

Abe T and Furuya M (2015) Winter speed-up of quiescent surge-type glaciers in Yukon, Canada. Cryosphere, 9, 1183-1190 (doi: 10.5194/tc-9-1183-2015)

Agarwal V and 5 others (2017) Area and mass changes of Siachen Glacier (East Karakoram). J. Glaciol., 63(237) 148-163 (doi: 10.1017/jog.2016.127)

Armstrong WH, Anderson RS and Fahnestock MA (2017) Spatial patterns of summer speedup on south central Alaska glaciers. Geophys. Res. Lett., 44, 9379-9388 (doi: 10.1002/2017 GL074370)

Aschwanden A and Blatter $\mathrm{H}$ (2005) Meltwater production due to strain heating in Storglaciären, Sweden. J. Geophys. Res. Earth Surf., 110, F04024 (doi: 10.1029/2005JF000328)

Benn D and Owen L (1998) The role of the Indian summer monsoon and the mid-latitude westerlies in Himalayan glaciation: review and speculative discussion. J. Geol. Soc., 155, 353-363

Bhambri R, Hewitt K, Kawishwar P and Pratap B (2017) Surge-type and surge-modified glaciers in the Karakoram. Sci. Rep., 7(1), 15391 (doi: 10.1038/s41598-017-15473-8)

Bieniek PA and 6 others (2016) Dynamical downscaling of ERAinterim temperature and precipitation for Alaska. J. Appl. Meteor. Climatol., 55, 635-654. (doi: 10.1175/JAMC-D-150153.1)

Björnsson H (1998) Hydrological characteristics of the drainage system beneath a surging glacier. Nature, 395(6704), 771-774 (doi: 10.1038/27384)

Bolch T and 11 others (2012) The state and fate of Himalayan glaciers. Science, 336, 310-314 (doi: 10.1126/science.1215828)

Bookhagen B and Burbank DW (2010). Toward a complete Himalayan hydrological budget: spatiotemporal distribution of snowmelt and rainfall and their impact on river discharge. J. Geophys. Res., 115 (doi: 10.1029/2009JF001426)

Copland L and 8 others (2009) Glacier velocities across the central Karakoram. Ann. Glaciol., 50(52) (doi: 10.3189/17275640 9789624229)

Copland L and 7 others (2011) Expanded and recently increased glacier surging in the Karakoram. Arct. Antarct. Alp. Res., 43, 503-516 (doi: 10.1657/1938-4246-43.4.503)

Dyurgerov MB and Meier MF (2005) Glaciers and the Changing Earth System: A 2004 Snapshot. Occasional Paper 58. Available online: https://instaar.colorado.edu/uploads/occasionalpapers/OP58_dyurgerov_meier.pdf

Farhan BS, Zhang Y, Ma Y, Guo Y and Ma N (2015) Hydrological regimes under the conjunction of westerly and monsoon climates: a case investigation in the Astore Basin, Northwestern Himalaya. Clim. Dyn., 44, 3015-3032 (doi: 10.1007/s00382014-2409-9)

Farr TG and 17 others (2007). The shuttle radar topography mission. Rev. Geophys. 45 (doi: 10.1029/2005RG000183)
Gardelle J, Berthier E and Arnaud Y (2012) Slight mass gain of Karakoram glaciers in the early twenty-first century. Nat. Geosci., 5, 322-325 (doi: 10.1038/NGEO1450)

Gray AL and Mattar KE (2000) Influence of ionospheric electron density fluctuations on satellite radar interferometry. Geophys. Res. Lett., 27(10), 1451-1454

Harrison WD and Post AS (2003) How much do we really know about glacier surging? Ann. Glaciol., 36, 1-6 (doi: 10.3189/ 172756403781816185)

Heid T and Kääb A (2012) Repeat optical satellite images reveal widespread and long term decrease in land-terminating glacier speeds. Cryosphere, 6, 467-478 (doi: 10.5194/tc-6-467-2012)

Herreid S and Truffer M (2016) Automated detection of unstable glacier flow and a spectrum of speedup behavior in the Alaska Range. J. Geophys. Res. Earth Surf., 121(1), 64-81 (doi: 10.1002/2015JF003502)

Hewitt K (1969) Glacier surges in the Karakoram Himalaya (central Asia). Can. J. Earth Sci., 6, 1009-1018 (doi: 10.1139/e69-106)

Hewitt K (2005) The Karakoram anomaly? Glacial expansion and 'elevation effect,' Karakoram Himalaya. Mt. Res. Dev. 25(4), 332-340

Hewitt K (2007) Tributary glacier surges: an exceptional concentration at Panmah Glacier, Karakoram Himalaya. J. Glaciol., 53, 181-188

Hewitt K (2011) Glacier change, concentration and elevation effects in the Karakoram Himalaya, upper Indus Basin. Mt. Res. Dev., 31, 188-200

Hewitt IJ (2013) Seasonal changes in ice sheet motion due to melt water lubrication. Earth Planet Sci. Lett., 371-372, 16-25 (doi: 0.1016/j.epsl.2013.04.022)

Hewitt K (2006) Glaciers of the Hunza Basin and related features. In Kreutzmann $\mathrm{H}$ (ed.) Karakoram in transition: culture, development and ecology in the Hunza Valley. Oxford University Press, Oxford, UK, 49-72

Hewitt K, Wake C, Young G and David C (1988) Hydrological investigations at Biafo Glacier, Karakorum Range, Himalaya; an important source of water for the Indus River. Ann. Glaciol., 13, 103-108 (doi: 10.1017/S0260305500007710)

Hoffman MJ and Price S (2014) Feedbacks between coupled subglacial hydrology and glacier dynamics. J. Geophys. Res. Earth Surf., 119, 414-436 (doi: 10.1002/2013JF002943)

Hoffman MJ and 9 others (2016) Greenland subglacial drainage evolution regulated by weakly connected regions of the bed. Nat. Commun., 7, 13903 (doi: 10.1038/ncomms1390)

Iken A and Bindschadler RA (1986) Combined measurements of subglacial water pressure and surface velocity of Findelengletscher, Switzerland: conclusions about drainage system and sliding mechanism. J. Glaciol., 32(110), 101-119

Iken A and Truffer M (1997) The relationship between subglacial water pressure and velocity of Findelengletscher, Switzerland, during its advance and retreat. J. Glaciol., 43(144), 328-338

Irvine-Fynn TDL, Moorman BJ, Williams JLM and Walter FSA (2006) Seasonal changes in ground penetrating radar signature observed at a polythermal glacier, Bylot Island, Canada. Earth Surf. Process. Landforms, 31, 892-909 (doi: 10.1002/esp.1299)

Jiskoot H (2011) Glacier surging. In Singh VP, Singh P and Haritashya UK eds. Encyclopedia of snow, ice and glaciers. Springer, Dordrecht, The Netherlands, 415-428,

Jiskoot H and Juhlin DT (2009) Surge of a small East Greenland glacier, 2001-2007, suggests Svalbard-type surge mechanism. J. Glaciol., 55(191), 567-570

Jiskoot H, Fox TA and van Wychen W (2017) Flow and structure in a dendritic glacier with bedrock steps. J. Glaciol., 63(241), 912-928

Joughin IR, Kwok R and Fahnestock MA (1998) Interferometric estimation of three-dimensional ice-flow using ascending and descending passes. IEEE Trans. Geosci. Remote. Sens., 36(1), 25-37 (doi: 10.1109/36.655315)

Kamb B (1987) Glacier surge mechanism based on linked cavity configuration of the basal water conduit system. J. Geophys. Res., 92, 9083-9100 (doi: 0148-0227/87/006B-632505.00) 
Kamb B and 7 others (1985) Glacier surge mechanism: 1982-1983 surge of variegated glacier, Alaska. Science, 227, 469-479

Kapnick SB, Delworth TL, Ashfaq M, Malyshev S and Milly P (2014) Snowfall less sensitive to warming in Karakoram than in Himalayas due to a unique seasonal cycle. Nat. Ceosci., 7, 834-840 (doi: 10.1038/ngeo2269)

Kessler MA and Anderson RS (2004) Testing a numerical glacial hydrological model using spring speed-up events and outburst floods. Geophys. Res. Lett., 31, L18503 (doi: 10.1029/ 2004GL020622)

Kobayashi T, Takada Y, Furuya M and Murakami M (2009) Locations and types of ruptures involved in the 2008 Sichuan earthquake inferred from SAR image matching. Geophys. Res. Lett., 36 (doi: 10.1029/2008GL036907)

Kyrke-Smith TM, Katz RF and Fowler AC (2015) Subglacial hydrology as a control on emergence, scale, and spacing of ice streams. J. Geophys. Res. Earth Surf. 120, 1501-1514 (doi: 10.1002/2015JF003505)

Lingle CS and Fatland DR (2003) Does englacial water storage drive temperate glacier surges? Ann. Glaciol., 36, 14-20 (doi: 10.3189/ 172756403781816464)

Matsuo K and Heki K (2010) Time-variable ice loss in Asian high mountains from satellite gravimetry. Earth Planet Sci. Lett., 290, 30-36 (doi: 10.1016/j.epsl.2009.11.053)

Mayer C, Fowler AC, Lambrecht A and Scharrek K (2011) A surge of North Gasherbrum Glacier, Karakoram, China. J. Glaciol., 57, 904-916

Mayewski PA and Jeschke PA (1979) Himalayan and transHimalayan glacier fluctuations since AD 1812. Arct. Alp. Res., 11, 267-287 (doi: 10.2307/1550417)

Müller F and Iken A (1973) Velocity fluctuations and water regime of Arctic valley glaciers. Int. Assoc. Sci. Hydrol. Publication 95, 165-182

Murray T, Strozzi T, Luckman A, Jiskoot H and Christakos P (2003) Is there a single surge mechanism? Contrasts in dynamics between glacier surges in Svalbard and other regions. J. Geophys. Res., 108, 2237 (doi: 10.1029/2002JB001906)

Palazzi E, Hardenberg JV, Terzago S and Provenzale A (2015) Precipitation in the Karakoram-Himalaya: a CMIP5 view. Clim. Dyn., 45, 21-45 (doi: 10.1007/s00382-014-2341-z)

Paul F (2015) Revealing glacier flow and surge dynamics from animated satellite image sequences: examples from the Karakoram. Cryosphere, 9(6), 2201-2214 (doi: 10.5194/tc-92201-2015)

Paul F, Strozzi T, Schellenberger T and Kääb A (2017) The 2015 surge of Hispar Glacier in the Karakoram. Remote Sens., 9(9), 888 (doi: 10.3390/rs9090888)

Pimentel S and Flowers GE (2010) A numerical study of hydrologically driven glacier dynamics and subglacial flooding. Proc. R. Soc. A (2011), 467, 537-558 (doi: 10.1098/rspa.2010. 0211)

Pimentel S, Flowers GE and Schoof CG (2010) A hydrologically coupled higher order flow band model of ice dynamics with a
Coulomb friction sliding law. J. Geophys. Res., 115, F04023 (doi: 10.1029/2009JF001621)

Pritchard H, Murray T, Luckman A, Strozzi T and Barr S (2005) Glacier surge dynamics of Sortebræ, east Greenland, from synthetic aperture radar feature tracking. J. Geophys. Res., 110 (doi: 10.1029/2004JF000233)

Quincey DJ and Luckman A (2014) Brief communication: on the magnitude and frequency of Khurdopin glacier surge events. Cryosphere, 8(3), 571-574 (doi:10.5194/tc-8-571-2014)

Quincey DJ and 5 others (2009) Ice velocity and climate variations for Baltoro Glacier, Pakistan. J. Glaciol., 55, 1061-1071

Quincey DJ and 5 others (2011) Karakoram glacier surge dynamics. Geophys. Res. Lett. 38 (doi: 10.1029/2011GL049004)

Quincey DJ, Glasser NF, Cook SJ and Luckman A (2015) Heterogeneity in Karakoram glacier surges. J. Geophys. Res. Earth Surf., 120, 1288-1300 (doi: 10.1002/2015JF003515)

Rankl M, Kienholz C and Braun M (2014) Glacier changes in the Karakoram region mapped by multimission satellite imagery. Cryosphere, 8, 977-989 (doi: 10.5194/tc-8-977-2014)

Raymond CF (1987). How do glaciers surge? A review. J. Geophys. Res., 92(B9), 9121-9134

Rignot E, Echelmeye K and Krabill W (2001) Penetration depth of interferometric synthetics aperture radar signals in snow and ice. Geophys. Res. Lett. 28, 3501-3504

Schoof C (2010) Ice-sheet acceleration driven by melt supply variability. Nature, 468, 803-806 (doi: 10.1038/nature09618)

Sevestre H and Benn DI (2015) Climatic and geometric controls on the global distribution of surge-type glaciers: implications for a unifying model of surging. J. Glaciol., 61(228), 646-662 (doi: 10.3189/2015JoG14J136)

Strozzi T, Luckman A, Murray T, Wegmuller $\mathrm{U}$ and Werner $\mathrm{CL}$ (2002) Glacier motion estimation using satellite-radar offsettracking procedures. IEEE Trans. Geosci. Remote Sens., 40, 2384-2391 (doi: 10.1109/TGRS.2002.805079)

Sund M, Eiken T, Hagen JO and Kääb A (2009) Svalbard surge dynamics derived from geometric changes. Ann. Glaciol., 50 (52), 50-60

Sund M, Lauknes TR and Eiken T (2014) Surge dynamics in the Nathorstbreen glacier system, Svalbard. Cryosphere, 8(2), 623-638

Wegmüller U and Werner CL (1997) Gamma SAR processor and interferometry software, in Proc. of the 3rd ERS Symposium, European Space Agency Special Publication. ESA SP-414, Florence, Italy, 14-21 March, 1686-1692

Yasuda T and Furuya M (2013) Short-term glacier velocity changes at West Kunlun Shan, Northwest Tibet, detected by synthetic aperture radar data. Remote Sens. Environ., 128, 87-106 (doi: 10.1016/j.rse.2012.09.021)

Yasuda T and Furuya M (2015) Dynamics of surge-type glaciers in West Kunlun Shan, Northwestern Tibet. J. Geophys. Res. Earth Surf., 120, 2393-2405 (doi: 10.1002/2015JF003511)

Zafar MU and 6 others (2016) Karakorum temperature out of phase with hemispheric trends for the past five centuries. Clim. Dyn., 46, 1943-1952 (doi: 10.1007/s00382-015-2685-z)

MS received 6 September 2017 and accepted in revised form 9 April 2018; first published online 11 May 2018 